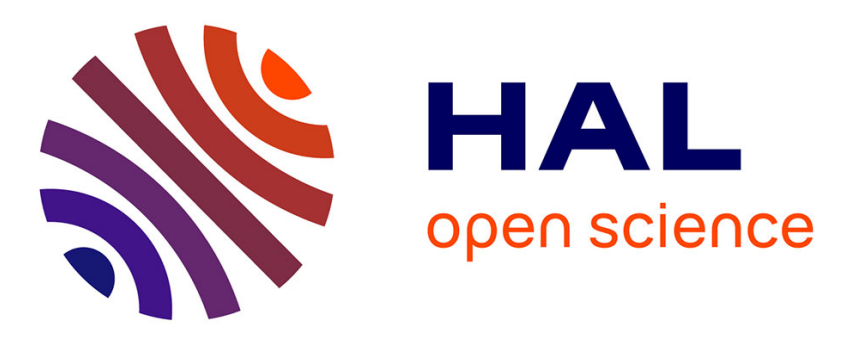

\title{
Bi-layered silane-TiO2/collagen coating to control biodegradation and biointegration of $\mathrm{Mg}$ alloys
}

Laura Córdoba, Christophe Hélary, Fatima Montemor, Thibaud Coradin

\section{To cite this version:}

Laura Córdoba, Christophe Hélary, Fatima Montemor, Thibaud Coradin. Bi-layered silane$\mathrm{TiO} 2 /$ collagen coating to control biodegradation and biointegration of $\mathrm{Mg}$ alloys. Materials Science and Engineering: C, 2019, 94, pp.126-138. 10.1016/j.msec.2018.09.032 . hal-02171960

\section{HAL Id: hal-02171960 https://hal.science/hal-02171960}

Submitted on 17 Jul 2019

HAL is a multi-disciplinary open access archive for the deposit and dissemination of scientific research documents, whether they are published or not. The documents may come from teaching and research institutions in France or abroad, or from public or private research centers.
L'archive ouverte pluridisciplinaire HAL, est destinée au dépôt et à la diffusion de documents scientifiques de niveau recherche, publiés ou non, émanant des établissements d'enseignement et de recherche français ou étrangers, des laboratoires publics ou privés. 


\section{Bi-layered silane- $\mathrm{TiO}_{2} /$ collagen coating to control biodegradation and biointegration of Mg alloys}

Laura C. Córdoba ${ }^{\mathrm{a}, \mathrm{b}, *}$, Christophe Hélary ${ }^{\mathrm{a}}$, Fátima Montemor ${ }^{\mathrm{b}}$, Thibaud Coradin ${ }^{\mathrm{a}}$

${ }^{a}$ Sorbonne Université, CNRS, Collège de France, Laboratoire de Chimie de la Matière Condensée de Paris, 4 place Jussieu, 75005 Paris, France

${ }^{b}$ CQE, Instituto Superior Técnico, Universidade de Lisboa, Av. Rovisco Pais, 1049-001 Lisboa, Portugal

\section{*Corresponding author: Laura C. Córdoba}

Postal Adress: Instituto Superior Técnico, Lab. de tecnologia electroquímica, Pavilhão de Minas, Piso 4, Av. Rovisco Pais, 1049-001 Lisboa, Portugal. Fax: +351 218417991

E-mail adresses: pitela@gmail.com (Laura C.Córdoba),christophe.helary@upmc.fr (Christophe Hélary), mfmontemor@ ecnico.ulisboa.pt (Fátima Montemor), thibaud.coradin@upmc.fr (Thibaud Coradin),

\footnotetext{
Abstract

Magnesium alloys have shown high potential as biodegradable implants for bone repair applications. However, their fast degradation in physiological media demands tuning their corrosion rate to accompany the natural tissue healing processes. Here, a new bi-layered silane$\mathrm{TiO}_{2} /$ collagen coating efficient in stabilizing and biofunctionalizing the surface of AZ31 and ZE41 $\mathrm{Mg}$ alloys is presented. Corrosion tests performed in cell culture medium over 7 weeks showed that the bi-layered coating promotes the formation of a stable layer of $\mathrm{Mg}(\mathrm{OH})_{2} / \mathrm{MgCO}_{3} / \mathrm{CaCO}_{3}$ that provides effective protection to the alloys at advanced immersion stages. The intrinsic reactivity of each alloy plus formation of transitory calcium phosphate phases, resulted in distinct corrosion behavior in the short term. Cell experiments showed that the bi-layered coating improved osteoblasts and fibroblasts proliferation compared to bare and silane- $\mathrm{TiO}_{2}$-coated alloys. Different responses in terms of cell adhesion could be related to the intrinsic corrosion rate of each alloy and some toxicity from the alloying elements. The results evidenced the complex interplay between alloy nature, coating-alloy combination and cell type. The silane- $\mathrm{TiO}_{2} /$ collagen coating showed to be a promising strategy to improve cell response and viability and to control degradation rate of Mg alloys in the long term.

Keywords: Magnesium alloys; Coatings; Collagen; Biodegradation; Cell-material interactions.
} 


\section{Introduction}

The use of $\mathrm{Mg}$ and its alloys as temporary metallic implants has been widely discussed in the literature [1-4]. The most remarkable features of Mg-based biomaterials are their mechanical properties, which reduce the shield stress effect commonly caused by traditional orthopaedic implants, and their ability to support new bone formation during the healing process [2]. When used as cardiovascular stents, Mg-based biomaterials reduced the risk of inflammation and restenosis [5]. In its elemental form, the presence of $\mathrm{Mg}$ in vivo is critical for metabolic activities, since it is the fourth most abundant cation in the body [6]. Therefore, $\mathrm{Mg}$ ions dissolved from materials can have a positive effect on cell survival and proliferation [7].

It has been shown that $\mathrm{Mg}$ alloys degradation process is mainly dependent on their elemental composition and on the corrosive environment [8, 9]. Their corrosion in aqueous solution is accelerated at $\mathrm{pH}$ below 11 while, at higher $\mathrm{pH}$, the formation of a protective hydroxide surface layer is promoted [8]. Since the in vivo $\mathrm{pH}$ is about 7, different strategies have been used to control the degradation rate of $\mathrm{Mg}$ alloys, such as impurity control, alloying selection, and surface coatings. Among these, the most popular consist of polymer layers incorporating hydroxyapatite particles [10-12] or in various calcium phosphate (CaP) coatings [13-15]. Electrodeposition, hydrothermal treatment, and spray coating are some commonly used techniques to deposit $\mathrm{CaP}$ coatings, but they often experience poor adhesion because of the high chemical reactivity and low melting point of metallic $\mathrm{Mg}$ [14]. Thick oxide coatings are also used, but they are susceptible to cracks and debris release, increasing the risk of thrombosis and local injuries of the tissues.

Nowadays, there is a growing interest in using biodegradable natural polymers for chemical-surface treatments on metallic biomaterials [15-17]. These biopolymers can be used to improve surface functionalities, such as controlled release of growth factors, cell adhesion, and enhanced tissue integration. Due to its high biocompatibility, cytocompatibility, and positive effects on cell activity, type I collagen has been widely used for the design of coatings on metallic biomaterials [18-24].

Synergistic approaches aiming at combining corrosion control with improved cell response of $\mathrm{Mg}$ alloys are still needed. Elaborating on the previously demonstrated ability of a barrier-type silane- $\mathrm{TiO}_{2}$ coating to slow down the corrosion of AZ31 and ZE41 Mg alloys in Simulated Body Fluid (SBF) [25], we developed here bi-layered coatings adding a collagen top-layer. They were 
characterized in terms of morphology, corrosion behavior, and influence on fibroblasts and osteoblasts in cell culture medium. On this basis, the role of each component on the corrosion evolution of the bi-layered alloys and their interplay was discussed on the short (1 week) and long term (up to 7 weeks). The here adopted strategy was to select $\mathrm{Mg}$ alloys of well-known properties (AZ31 and ZE41) in order to focus on the surface functionalization features, such as surface chemistry, topography and cell/biomaterial interactions, among others. In practical terms, that is to say the phenomena that occur at the implant/tissue interface. Thus, the final strategy implemented could then be extrapolated to other type of $\mathrm{Mg}$ alloys and, potentially, to other type of biomaterials that require improved surface properties.

\section{Materials and methods}

\subsection{Materials and substrates preparation}

AZ31 (3 wt.\% Al, 1 wt.\% Zn, 0.3 wt.\% Mn) and ZE41 (4 wt.\% Zn, 1 wt.\% RE, 0.7 wt.\% Zr) magnesium alloys were obtained as extruded rods (Magnesium Elektron Company, UK). (3glycidoxypropyl)trimethoxysilane ( $\geq 98 \%$ GPTMS, Aldrich), titanium IV iso-propoxide ( $\geq 97 \%$ TIP, Aldrich), acetylacetone, and 2-propanol ( $\geq 99.5 \%$ ACS reagent, Sigma-Aldrich) were analytical grade. The metallic coupons were cut into discs $(\varnothing 25 \mathrm{~mm}$ x $3 \mathrm{~mm}$ thick) and sequentially polished from 180 up to 1000 SiC grit papers. A surface pre-treatment by immersion in $12 \%$ HF (puriss p.a., Sigma-Aldrich) was performed to promote the formation of a layer of $\mathrm{MgF}_{2}$ [25]. The $12 \% \mathrm{HF}$ pre-treated alloys were denoted as AZ31 and ZE41. All pre-treated samples were thoroughly washed with ethanol ( $\geq 96 \%$, Sigma-Aldrich) and dried with air stream.

\subsection{Preparation of bi-layered coatings}

The hybrid sol was obtained by mixing pre-hydrolyzed GPTMS and TIP solutions in a volume ratio of 1.5:1, respectively [25]. The silane-based alkolsol was prepared by acidic hydrolysis ( $\mathrm{pH}$ 0.5) of GPTMS in 2-propanol (volume ratio 1:1) at room temperature. The second alkolsol was prepared by the hydrolysis of 70\% TIP solution in 2-propanol in the presence of acetylacetone (Acac) and adding aqueous solution of $\mathrm{HNO}_{3}(\mathrm{pH} 0.5)$ with a final volume ratio TIP:Acac: $\mathrm{H}_{2} \mathrm{O}$ of 5:3:1. After 1 hour aging, the hybrid sol was deposited onto the pre-treated alloys by dip-coating at a speed of $17 \mathrm{~cm} \cdot \mathrm{min}^{-1}$ after 30 seconds of total immersion. The sol-gel coated 
coupons, denoted as AZ31_S and ZE41_S, were then cured at $120^{\circ} \mathrm{C}$ for 90 minutes in air atmosphere. They were sterilized by soaking in ethanol for 30 minutes.

A solution of type I collagen (extracted and purified from rat tail tendon) was prepared in $0.005 \mathrm{M}$ acetic acid at a $3 \mathrm{mg} \cdot \mathrm{mL}^{-1}$ concentration [26]. Top layers were deposited by manually dipping twice the sterilized sol-gel coated coupons into this solution, with a 15 min intermediate drying step at room temperature. The bi-layered samples with collagen were denoted as AZ31_SC and ZE41_SC.

\subsection{Surface characterization}

After gold sputtering, the samples were examined by Hitachi S-3400N scanning electron microscopy (SEM). Plane and cross-sections images were recorded to characterize the asdeposited coatings morphologies and thickness. For chemical characterization of corroded surfaces after the corrosion experiments, energy dispersive spectroscopy (EDS) microanalysis was used.

Bruker® Atomic force microscope (AFM) was used to determine the surface roughness and to obtain additional morphological information. Silicon probes (NanoAndMore, USA) in tapping mode at room temperature were used to obtain topographical and phase contrast unfiltered images.

\subsection{Electrochemical measurements}

Electrochemical impedance spectroscopy (EIS) was used to characterize the corrosion behavior of all surface conditions on both AZ31 and ZE41 alloys. EIS experiments were performed in the culture medium described in section 2.5 at $37 \pm 1^{\circ} \mathrm{C}$ for 7 weeks. A conventional three electrode electrochemical cell with the sample as working electrode $\left(3.1 \mathrm{~cm}^{2}\right.$ exposed area), a saturated calomel as reference, and a platinum coil as counter electrode were used. Data were recorded using a Gamry Ref. 600 potentiostat at open circuit potential scanning from $10^{5} \mathrm{~Hz}$ down to $10^{-2} \mathrm{~Hz}$. To avoid electromagnetic interferences, all measurements were performed in a Faraday cage. The fitting parameters were obtained by analyzing the results by ZView3® software.

\subsection{Cell culture}


Normal human dermal fibroblasts (NHDF) and primary human osteoblasts (HOB) were cultured in Dulbecco's modified Eagle's medium (DMEM), 10\% fetal calf serum, 100 units $\mathrm{mL}^{-1}$ penicillin, $100 \mu \mathrm{g} \mathrm{ml}^{-1}$ streptomycin and $0.25 \mu \mathrm{g} \mathrm{ml}^{-1}$ Fungizone (all components Gibco BRL). Tissue culture plates were kept for several days at $37^{\circ} \mathrm{C}$ in a humidified atmosphere (95\% air) with $5 \% \mathrm{CO}_{2}$. Fibroblasts and osteoblasts were enzymatically detached from culture flasks at $70-80 \%$ confluence by treatment with $0.1 \%$ trypsin and $0.02 \%$ EDTA. Then, the cells were rinsed, resuspended in DMEM, and used to test the cell response to the different surface compositions.

A new sample setup was developed to perform the cell viability/proliferation assays. To confine the cell suspension onto the surface of interest, a sterilized polyethylene cylinder $(\varnothing 20$ $\mathrm{mm} x$ height $10 \mathrm{~mm}$ ) was stuck on top of the coupons using a medium-viscosity fast curing silicone (Kwik-Sil, World Precision Instruments) at room temperature. The sets were placed into 6-well flat-bottomed cell culture plates. Cells were seeded at a density of $4 \times 10^{4}$ cells $\cdot \mathrm{cm}^{-2}$ in culture medium onto pre-treated (AZ31 and ZE41), sol-gel coated (AZ31_S and ZE41_S), and bi-layered coupons (AZ31_SC, ZE41_SC). Fibroblast cultures were incubated $\left(37^{\circ} \mathrm{C}, 95 \%\right.$ air with $\left.5 \% \mathrm{CO}_{2}\right)$ for 1 and 3 days, while osteoblast cultures were incubated for 1, 3, and 7 days. Cell culture plates were used as positive control. Each surface condition was performed in triplicate and results expressed as the arithmetic mean \pm standard deviation.

\subsection{Cell viability assays}

AlamarBlue ${ }^{\circledR}$ reagent was used at selected time-points to characterize cell viability/proliferation. For this, the culture medium was removed and $300 \mu \mathrm{L}$ of fresh DMEM with $10 \%(\mathrm{v} / \mathrm{v})$ of AlamarBlue was added to the cells and incubated $\left(37^{\circ} \mathrm{C}, 95 \%\right.$ air with $\left.5 \% \mathrm{CO}_{2}\right)$ for 4 hours. Then, the solution was collected and $700 \mu \mathrm{L}$ of fresh DMEM was added. The optical absorbance was measured at $570 \mathrm{~nm}$ and $600 \mathrm{~nm}$ by UVIKON XL spectrophotometer. The percentage of reduction of resazurin was calculated following the formula provided by the manufacturer. The resazurin reduction assay was simultaneously performed on samples without cultured cells to check for possible interference from the Mg alloys or the sol-gel coating. After 4 hours of incubation, the reagent was still non-fluorescent blue on these conditions.

\subsubsection{Indirect contact assays}


To further elucidate the parameters influencing cell viability, indirect contact assays were carried out. Pre-treated disc ( $12 \% \mathrm{HF}$ bath) of both alloys were incubated at $37 \pm 1{ }^{\circ} \mathrm{C}$ in cell culture medium for 7 days and aliquots of supernatants collected at day 1 (S1), 3 (S3), and 7 (S7) were tested on cells adhering onto multi-well culture plates. First, fibroblasts and osteoblasts were seeded in multi-well plates and incubated for $24 \mathrm{~h}$ to allow normal adhesion; next, aliquots of supernatants (S1, S3, S7) were added to adhered cells and incubated for 7 days. Cell viability was measured at day 1, day 3 and day 7 for each set of cells in supernatants.

\subsection{Cell morphology characterization}

For SEM observation, the cultured cells were fixed with $1.5 \%$ glutaraldehyde in $0.1 \mathrm{M}$ sodium cacodylate buffer ( $\mathrm{pH}$ 7.3) for 1 hour, dehydrated through an ascending ethanol series of $50 \%, 70 \%$, and $95 \%$ for 5 minutes each, followed by two 10 min baths in $100 \%$ ethanol. The samples were dried inside a desiccator for 24 hours. After gold sputter coating, the samples were observed by SEM to determine cell morphology and distribution.

Additional observations were performed using fluorescence microscopy, allowing for simultaneous morphological studies and viability tests. The samples were first fixed with $4 \%$ paraformaldehyde (PFA) in PBS for 1 hour. Then, cells were rinsed three times with PBS to remove residual PFA. Viable and dead cells were stained using a double staining Live/dead Kit (Sigma-Aldrich). Cells imaging was performed with AXIO D1 Imager fluorescence microscope with $490 \mathrm{~nm}$ excitation signal to simultaneously monitor viable and dead cells.

\section{Results}

\subsection{Substrates and bi-layered coatings surface characterization}

The morphology of the as-deposited silane- $\mathrm{TiO}_{2}$ coating on both AZ31 and ZE41 alloys was observed by SEM and the results are shown in Fig. 1a,b. The insets in both figures show the morphology of pre-treated alloys underneath the sol-gel coating. The roughness of AZ31 and ZE41 measured by AFM was $406 \pm 99 \mathrm{~nm}$ and $356 \pm 31 \mathrm{~nm}$, respectively. The $\mathrm{MgF}_{2}$ layer formed during soaking in $12 \% \mathrm{HF}$ was thin enough not to modify the original alloys roughness. AFM characterization of the $\mathrm{MgF}_{2}$ layers on $\mathrm{AZ31}$ and $\mathrm{ZE} 41$ alloys was already reported elsewhere [25]. After deposition of the silane-based layer, the coating surface was smooth without evidence of micro-cracks or micro-pores; surface roughness was $R_{q}=26 \pm 9 \mathrm{~nm}$. 


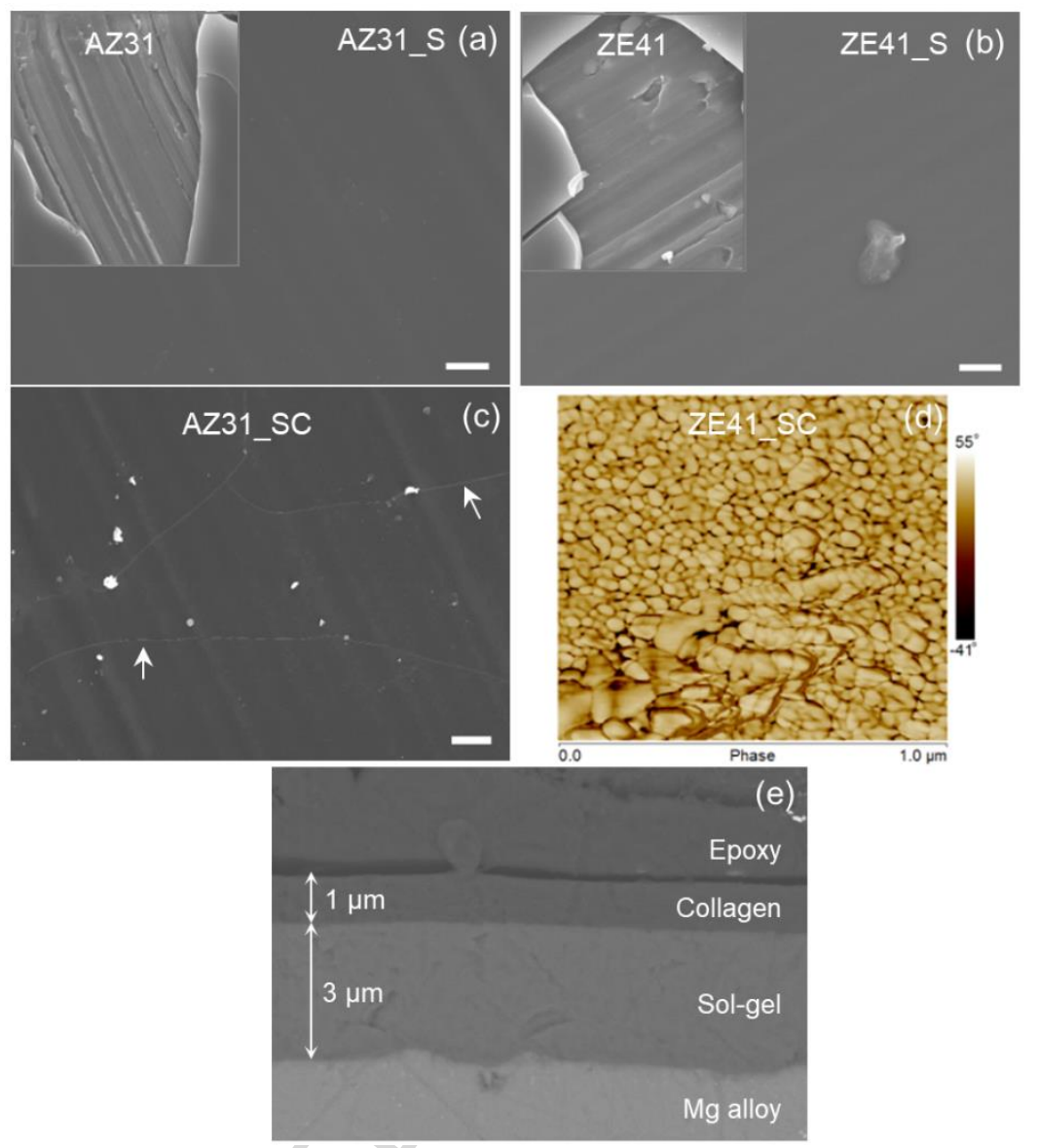

Fig. 1. SEM images of sol-gel coated and bi-layered alloys: (a) AZ31_S, (b) ZE41_S, (c) ZE41_SC (scale bar = 10 $\mu \mathrm{m}$ ). (d) AFM topographic image of ZE41_SC. The insets in (a) and (b) show the topography of the pre-treated alloys underneath the coating. (e) Cross-sectional backscattered electron image of the bi-layered systems deposited on the Mg alloys.

Finally, the top-most as-deposited collagen layer resulted in a homogeneous surface, as evidenced from SEM image in Fig. 1c. The cracks observed in Fig. 1c (see arrows) are likely to form under vacuum exposure in the SEM chamber. Additional topographical AFM imaging showed that the collagen layer consisted of a rather smooth-homogeneous agglomeration of nanoparticles forming a film of average roughness $R_{q}=6.6 \pm 0.8 \mathrm{~nm}$. These particles exhibited an average size of $90 \mathrm{~nm}$ (Fig. 1d). The morphology of the as-deposited collagen layer was identical for both AZ31_SC and ZE41_SC samples. Further imaging of samples cross-section showed that the thickness of the bi-layered systems was homogeneous and reproducible, irrespectively of the 
alloy. The bottom sol-gel coating was $3.3 \pm 0.2 \mu \mathrm{m}$-thick and the top-most collagen layers $1.3 \pm$ $0.1 \mu \mathrm{m}$-thick (Fig. 1e).

\subsection{Corrosion behaviour}

\subsubsection{Electrochemical monitoring}

$\mathrm{Mg}$ alloys intended for biomedical applications have been widely studied in several inorganic simulated body fluid solutions. However, body physiological medium has much more complex composition than inorganic solutions making reasonable to presume that organic components such as proteins, amino acids, lipids, and even cells may modify the corrosion response of $\mathrm{Mg}$ alloys. Thus, to consider a more realistic approach, in this work, the corrosion evolution was studied by EIS in DMEM at $37 \pm 1^{\circ} \mathrm{C}$ for 7 weeks.

EIS results for all surface conditions are presented as Bode plots in Fig. 2. Important differences between both pre-treated alloys were observed. First, low frequency $\left(10^{-2}-10^{-1} \mathrm{~Hz}\right)$ impedance modulus after $2 \mathrm{~h}$ of immersion was similar for both alloys $\left(\sim 3 \times 10^{4} \Omega \cdot \mathrm{cm}^{2}\right)$. Afterwards, the impedance of AZ31 increased up to $10^{6} \Omega \cdot \mathrm{cm}^{2}$ from $2 \mathrm{~h}$ to 3 days and remained quite stable over 7 weeks, indicating the formation of a layer of stable corrosion products, confirmed by the formation of a second time constant between 10-10 $\mathrm{Hz}$ low frequency (phase angle values in Fig. 2a). For ZE41, the impedance dropped by one order of magnitude after 3 days. The sharpening of the time constant around $10 \mathrm{~Hz}$ between 2 and 7 weeks (phase angle values in Fig. 2b) indicated the formation of a corrosion products layer, but less protective compared to that of AZ31. 

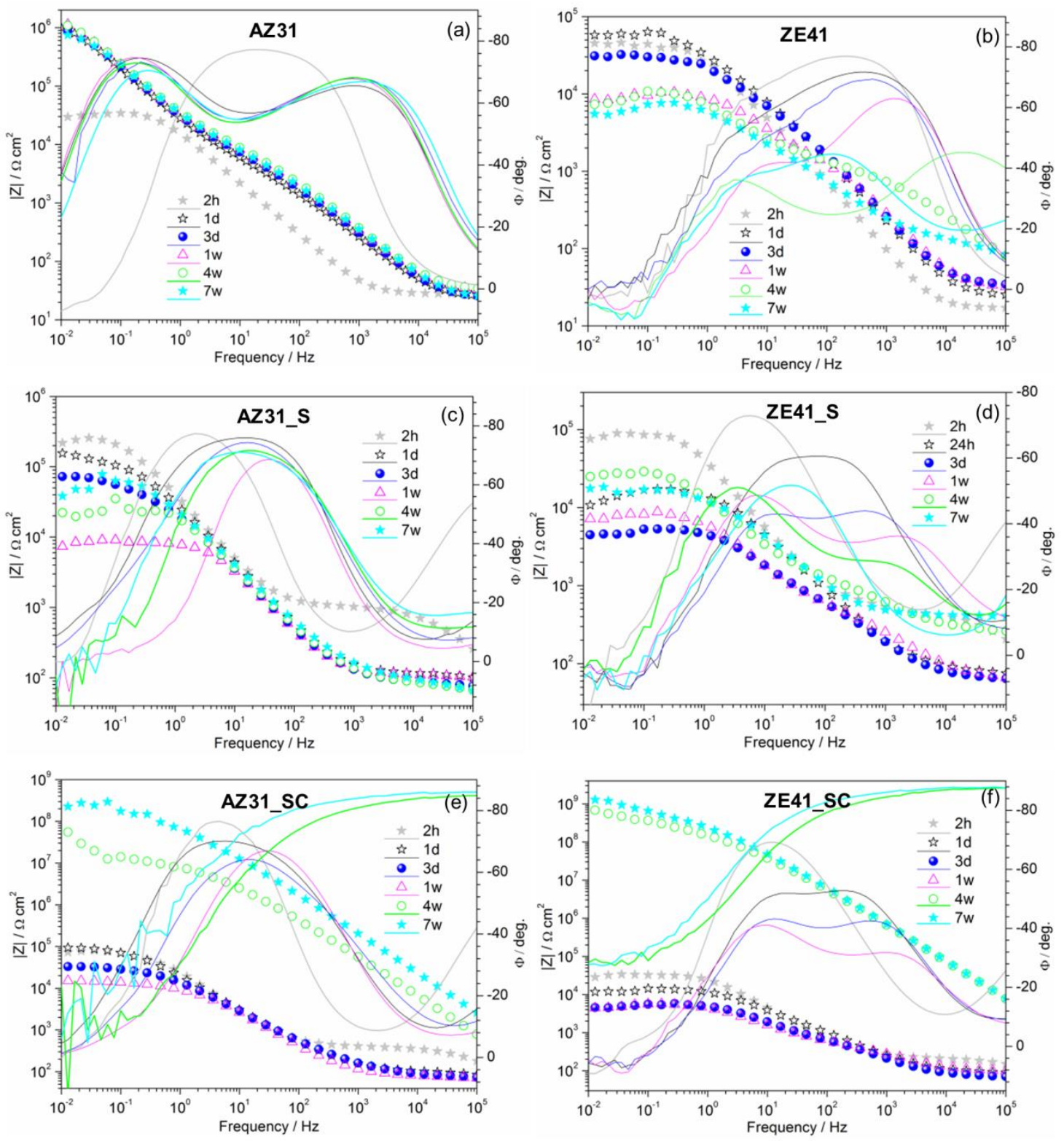

Fig. 2. Bode plots of the different surface conditions for both alloys immersed in DMEM at $37^{\circ} \mathrm{C}$ for 7 weeks. Symbols are impedance values $(|\mathrm{Z}|)$ and lines are phase angle values $(\phi)$.

The initial increase of the low frequency $(<10 \mathrm{~Hz})$ impedance values of AZ31_S and ZE41_S (Fig. 2c-d) compared to the pre-treated samples, confirmed that the sol-gel coating provided a protective barrier effect. Unlike AZ31, AZ31_S low frequency impedance decreased gradually over 1 week. The evolution of the time constant at higher frequencies (particularly the phase angle at frequencies above $10^{3} \mathrm{~Hz}$ ) indicated the deterioration of the coating barrier properties (Fig. 2c). The sol-gel coating underwent faster deterioration on ZE41_S during the first 3 days (Fig. 2d). 
However, after 1 week, an increase of the impedance together with the formation of an additional time constant at middle-low frequencies $(1-10 \mathrm{~Hz})$ evidenced the onset and growth of a layer of corrosion products at the coating/substrate interface. The differences between AZ31_S and ZE41_S showed that the coating protection ability depended upon the alloy.

The Bode plots in Fig. 2e and Fig. 2f showed that the collagen layer was highly beneficial to the long-term stability of the alloys, with low frequency impedance reaching values of more than three (AZ31_SC) to four (ZE41_SC) orders of magnitude higher compared to pre-treated and sol-gel coated materials after 7 weeks of immersion. At early immersion, the presence of collagen did not reveal detrimental effects on the sol-gel coating barrier properties. Instead, it seemed to slow down the coating deterioration.

\subsubsection{Composition and morphology of corroded surfaces}

After EIS experiments all corroded surfaces were characterized by SEM and its elemental composition was assessed by the EDX technique. Fig. 3 depicts the morphology of the corroded substrates after 7 weeks in DMEM at $37 \pm 1{ }^{\circ} \mathrm{C}$. In terms of morphology and composition, a wide variety of corrosion products was observed, even when comparing between two different surface conditions for the same alloy. In most cases, the corrosion products seemed to be composed of $\mathrm{Mg}(\mathrm{OH})_{2}, \mathrm{MgCO}_{3}$, and $\mathrm{CaCO}_{3}$. Since $\mathrm{EDX}$ is a technique for elemental analysis, certainly it is necessary to perform further characterization using additional techniques that allow determining the precise composition of the deposits. Thus, we stress that the here reported results in terms of corrosion products suggest - but not determine - their composition in a qualitative order.

Additional X-ray diffraction measurements (not shown) of the corroded samples evidenced diffraction peaks only from the substrates, suggesting that the corrosion layers were predominantly amorphous. In a previous work [25] we discussed about poorly crystalline corrosion layers formed on pre-treated and sol-gel coated AZ31 and ZE41 alloys after 7 weeks of immersion in SBF. Broad diffraction peaks as well as broad Raman peaks of decreased intensity suggested poor crystallinity of these layers [25]. Some studies [36, 37] have discussed about the reaction of former $\mathrm{Mg}(\mathrm{OH})_{2}$ with $\mathrm{Cl}^{-}$to produce highly soluble $\mathrm{MgCl}_{2}$ which at advanced immersion periods (>1 week) may result in a poorly crystalline corrosion layer. 

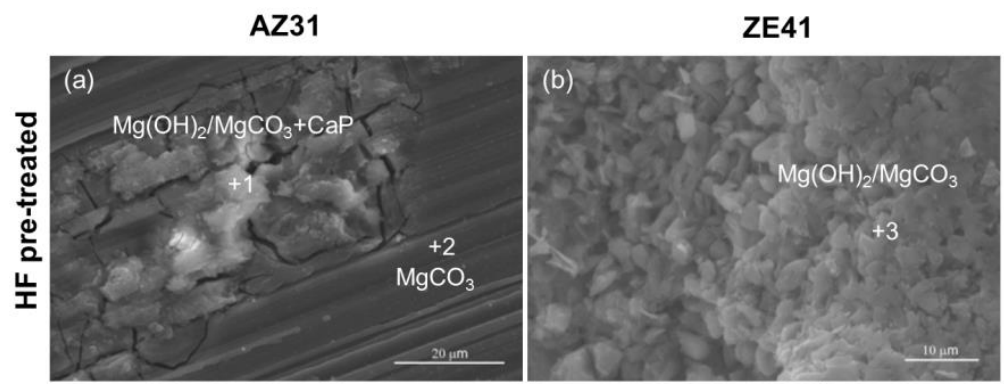

\begin{tabular}{lcccc}
\hline \multicolumn{5}{c}{ Atomic \% } \\
\hline Point & +1 & +2 & +3 \\
\hline $\mathrm{Mg}$ & 5.51 & 47.73 & 12.58 \\
$\mathrm{C}$ & 32.17 & 39.43 & 43.17 \\
$\mathrm{O}$ & 45.24 & 8.40 & 42.24 \\
$\mathrm{Ca}$ & 9.37 & 0.61 & 1.17 \\
$\mathrm{P}$ & 5.49 & 0.73 & 0.59 \\
$\mathrm{Cl}$ & - & - & 0.15 \\
$\mathrm{Al}$ & 0.87 & 0.84 & - \\
$\mathrm{Zn}$ & 0.23 & 0.42 & 0.10 \\
\hline \multicolumn{5}{c}{ Atomic $\%$} \\
\hline Point & +4 & +5 & +6 \\
\hline $\mathrm{Mg}$ & 17.15 & 20 & 19.52 & 18.89 \\
$\mathrm{C}$ & 20.86 & 18.29 & 16.43 & 28.65 \\
$\mathrm{O}$ & 56.88 & 44.36 & 58.65 & 50.19 \\
$\mathrm{Ca}$ & 2.17 & 16.43 & 0.48 & 0.69 \\
$\mathrm{P}$ & - & 0.53 & 0.36 & 0.53 \\
$\mathrm{Cl}$ & 0.50 & - & \multicolumn{1}{c}{-} & - \\
$\mathrm{Al}$ & 2.15 & - & - & - \\
$\mathrm{Zn}$ & 0.27 & 0.39 & 1.62 & 1.05 \\
\hline
\end{tabular}
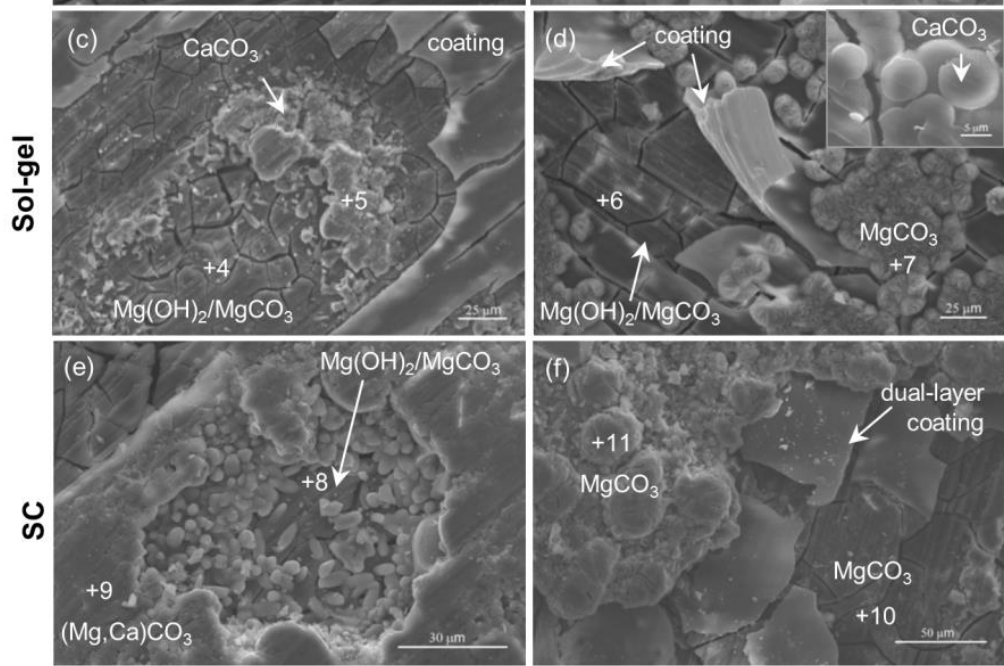

\begin{tabular}{ccccc}
\hline \multicolumn{5}{c}{ Atomic \% } \\
\hline Point & +8 & +9 & +10 & +11 \\
\hline $\mathrm{Mg}$ & 17.46 & 5.07 & 16.63 & 13.55 \\
$\mathrm{C}$ & 30.67 & 30.72 & 24.80 & 30.67 \\
$\mathrm{O}$ & 48.46 & 53.87 & 56.44 & 54.56 \\
$\mathrm{Ca}$ & 0.62 & 10.05 & 0.96 & 0.59 \\
$\mathrm{P}$ & 0.23 & 0.05 & 0.09 & 0.11 \\
$\mathrm{Cl}$ & 0.21 & - & - & - \\
$\mathrm{Al}$ & 2.03 & - & - & - \\
$\mathrm{Zn}$ & 0.26 & 0.17 & 1.0 & 0.51 \\
\hline
\end{tabular}

Fig. 3. Morphology of corroded substrates after EIS experiments in DMEM for 7 weeks at $37 \pm 1^{\circ} \mathrm{C}$. Left column shows all surface conditions for AZ31 (a,c,e) and middle column all surface conditions for ZE41 (b,d,f). Right column shows EDX results of indicated points. The inset in (d) shows the aggregates found on the corrosion layer of ZE41_S.
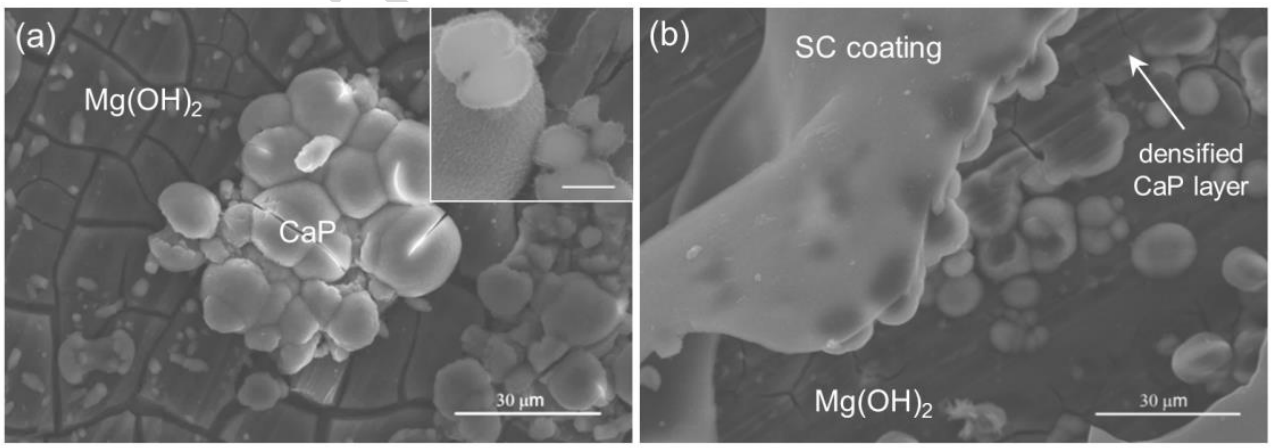

Fig. 4. SEM images of the corrosion products layer of (a) AZ31_SC and (b) ZE41_SC after 1 week of EIS experiments in DMEM at $31 \pm 1^{\circ} \mathrm{C}$. The inset in (a) shows the cross-section of a sphero-aggregate (scale bar: $2.5 \mu \mathrm{m}$ ). 


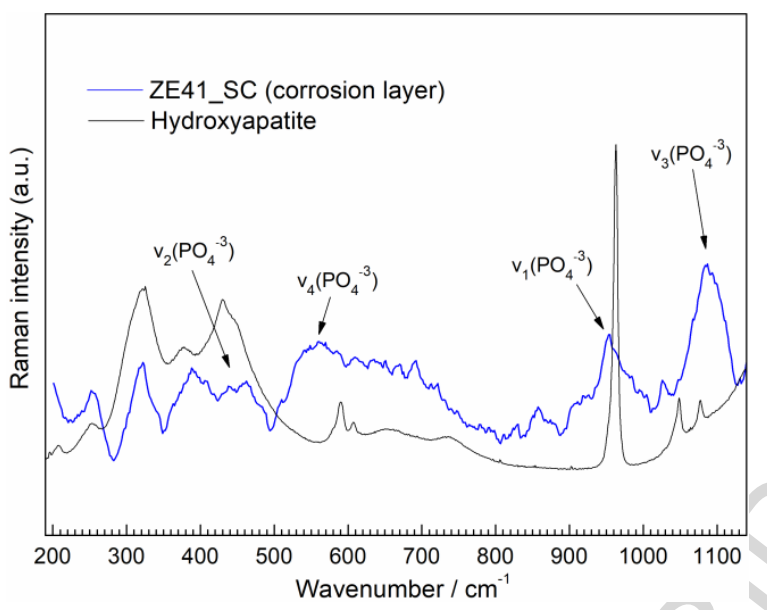

Fig. 5. Raman spectra of the corrosion layer of ZE41_SC after 1week of EIS experiments in DMEM compared to RUFF $^{\mathrm{TM}}$ [27] pattern of hydroxyapatite.

For a better understanding of the corrosion evolution, additional characterization of the corrosion products was made after week $1^{\text {st }}$ of immersion in DMEM. Fig. 4 shows the morphology of the corrosion products of the SC bi-layered alloys. Spherical aggregates rich in Ca and $\mathrm{P}$ grew over a dense $\mathrm{Mg}(\mathrm{OH})_{2}$ layer. Raman analysis of the corrosion layer on ZE41_SC after 1 week (Fig. 5) confirmed the presence of phosphate groups. The characteristic $\mathrm{PO}_{4}^{3-}$ band $\left(v_{1}\right)$ of hydroxyapatite (HAP, RUFF ${ }^{\mathrm{TM}}$ pattern [27]) appeared about $950 \mathrm{~cm}^{-1}$. This peak represents the symmetric stretching mode of the $\mathrm{P}-\mathrm{O}$ bond. However, variations of the band around $950 \mathrm{~cm}^{-1}$ such as broadening, are normally associated to poorly crystalline samples since this peak represents the grade of crystallinity of the material $[38,39]$. In the present case, EDX results (not shown) revealed that the spheroaggregates in Fig. 4 have $\mathrm{Mg}$ and $\mathrm{Zn}$ content. Non stoichiometric CaPs can be obtained in the presence of foreign ions [38] such as carbonates, chlorides and oxides, among others. CaPs that exhibit different ions substitutions and vacancies can alter the regularity of the lattice and cause variations in the Raman spectra, as observed in Fig. 5, suggesting the presence of a modified HAP.

It is important to remark that such CaP aggregates (Fig. 4) were found on all the coated conditions except for pre-treated alloys.

\subsubsection{Numerical fitting of corrosion data}

To further elucidate the corrosion mechanisms of the bi-layered alloys, numerical fitting of the corrosion data was performed. The equivalent circuits used to fit the results are depicted in 
Fig. 6a. Constant phase elements (CPE) accounting for the non-homogeneous behavior of the working electrode were used instead of pure capacitors. Three time constants were included in the equivalent circuits in Fig. 6a: (i) one at high frequencies describing the barrier properties of the bi-layered coating, (ii) a second one in the middle frequency range describing the properties of an interfacial layer that may include the insoluble corrosion products, (iii) and a third one assigned to the corrosion activity. The $\chi^{2}$ of the regression was around $10^{-3}$. The data extracted from numerical fitting are plotted in Fig. 6b-e. In Fig. 6b and Fig. 6d, $\mathrm{R}_{S C}$ and $\mathrm{R}_{\mathrm{IL}}$ account for the resistance of the electrolyte inside the bi-layered coating pores (SC: sol-gel+collagen) and for the resistance of the corrosion layer (IL: interfacial layer), respectively. Likewise, CPESC and CPEIL (Fig. 6c and Fig. 6e) account for the capacitive response of the sol-gel+collagen coating and of the corrosion layer, respectively.

During the first $24 \mathrm{~h}$ of immersion, $\mathrm{R}_{\mathrm{SC}}$ of both bi-layered alloys first increased but gradually decreased afterwards, while their CPESC increased, indicating deterioration of the coating barrier properties. The $\mathrm{CPE}_{\mathrm{SC}}$ evolution suggested that at early immersion deterioration was faster on ZE41_SC compared to AZ31_SC. Between $1^{\text {st }}$ and $3^{\text {rd }}$ week, RSC of AZ31_SC increased from $\sim 10^{2} \Omega \cdot \mathrm{cm}^{2}$ to $\sim 10^{6} \Omega \cdot \mathrm{cm}^{2}$. This increase could be due to the blockage of the coating pores by insoluble corrosion products. Over longer periods, RSC of AZ31_SC became stable, showing that the barrier properties of the coating either did not deteriorate or, instead deteriorated much slower. The latter could be confirmed by the steady CPESC response of AZ31_SC (Fig. 6c) after 2 weeks. A similar behaviour was observed on the long term (i.e. after 4 weeks) for ZE41_SC (Fig. 6d,e). However, when compared to AZ31_SC, both R SC $_{\text {and CPESC }}$ showed a sharp decrease and increase, respectively, between $2^{\text {nd }}$ and $3^{\text {rd }}$ week.

$\mathrm{R}_{\mathrm{IL}}$ and CPE $\mathrm{IL}$ in Fig. 6b-c showed that the corrosion layer of AZ31_SC provided more effective corrosion protection to the substrate, as confirmed by the increase of $\mathrm{R}_{\mathrm{IL}}$ over immersion. From $2 \mathrm{~h}$ to 3 weeks it seemed that the AZ31_SC corrosion layer underwent thickening and probably densification, as suggested by the CPEIL decrease and $\mathrm{R}_{\mathrm{IL}}$ increase, respectively. The same was observed for the corrosion layer of ZE41_SC until 2 weeks, thereafter wider fluctuations of $\mathrm{R}_{\mathrm{IL}}$ and CPE $\mathrm{IL}$ were observed between the $2^{\text {nd }}$ and $4^{\text {th }}$ week (Fig. 6d-e). Since the ILs of both bilayered alloys presented identical composition (see Fig.3) thus those stability differences could be related to incorporation of alloying elements into the corrosion products. 
(a)
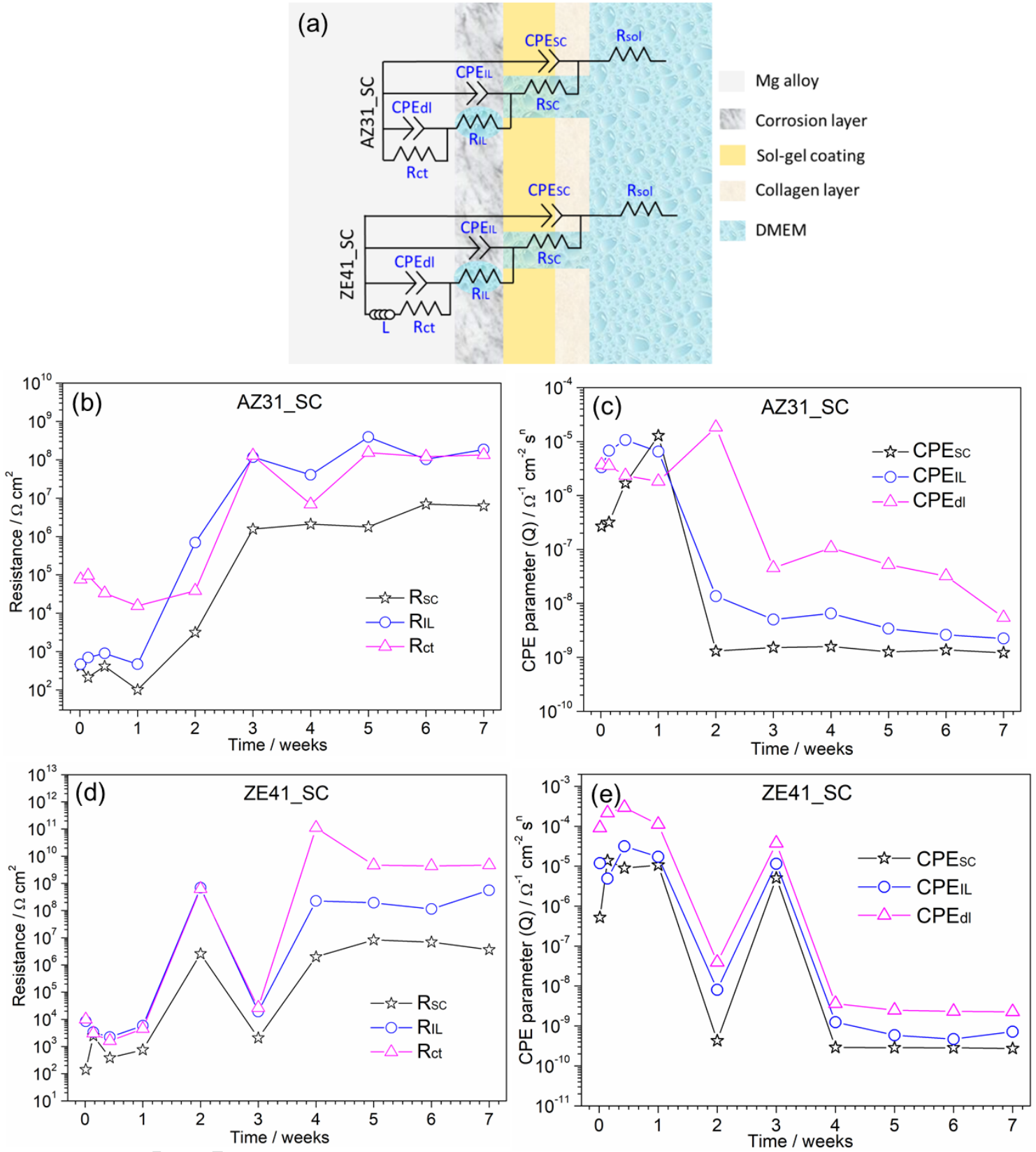

Fig. 6. (a) Equivalent circuits used to fit EIS data of AZ31_SC and ZE41_SC and values extracted from the fitting. (b),(d) show evolution of resistance and (c),(e) CPE parameter Q for AZ31_SC and ZE41_SC, respectively.

The evolution of $\mathrm{R}_{\mathrm{ct}}$ and $\mathrm{CPE}_{\mathrm{dl}}$ of both alloys showed that at early immersion the corrosion resistance of AZ31_SC was governed by the response of the substrate, whereas at advanced immersion stages the corrosion response was determined by the stability of the corrosion layer (Fig. 6b-c). The higher corrosion resistance of AZ31 compared to the ZE41 could delay coating delamination, owing to the slower rate of formation of the corrosion layer. On the other hand, $\mathrm{R}_{\mathrm{ct}}$ 
and $\mathrm{CPE}_{\mathrm{dl}}$ evolution in Fig. 6d-e showed that the corrosion response of ZE41_SC was mainly controlled by the barrier properties of the corrosion products layer. Faster deterioration of the coating barrier properties under this condition along with its higher reactivity, promoted the formation of the corrosion layer at earlier stages.

\subsection{Cell responses to the surface conditions}

\subsubsection{Cell viability on uncoated alloys}

The fate of fibroblasts and osteoblasts seeded on the pre-treated alloys was first evaluated. After one day, fibroblasts adhere on the surface of the pre-treated alloys in a similar extent compared to those on the control culture plate, as indicated by a comparable cell activity in Fig. 7a. After 3 days, the population of viable fibroblasts decreased on AZ31, while it increased on ZE41 and on the control. Osteoblasts viability on the uncoated alloys after one day indicated similar adhesion on both pre-treated materials (Fig. 7b). However, the detrimental effect of AZ31 on osteoblast adhesion and proliferation was evidenced after 3 days, whereas no adverse effect of ZE41 on osteoblasts could be observed over 7 days.
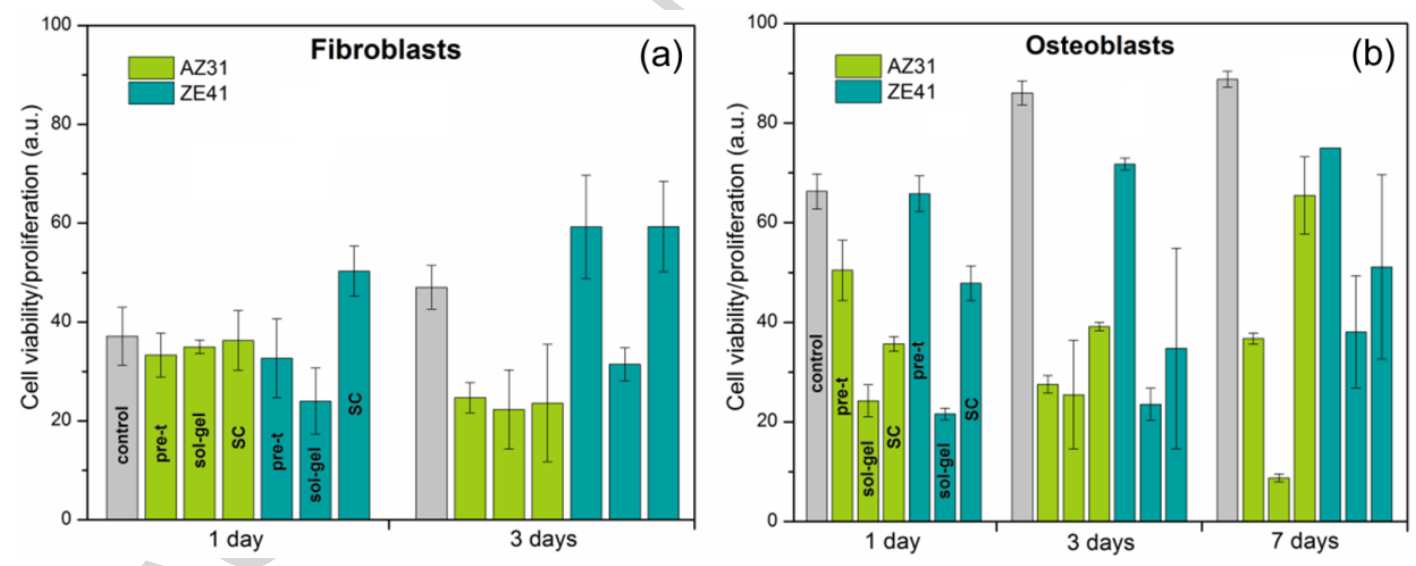

Fig. 7. Cell viability of (a) fibroblasts and (b) osteoblasts seeded on the different surfaces, as obtained by the Alamar Blue test. pre-t: $12 \% \mathrm{HF}$ pre-treated, sol-gel: silane- $\mathrm{TiO}_{2}, \mathrm{SC}$ : sol-gel+collagen. Values are given as the arithmetic mean \pm standard deviation based on three replicates.

As observed from indirect contact assays in Fig. 8, supernatants from AZ31 seemed toxic for fibroblasts after 1 day and for osteoblasts after 3 days, hindering cells proliferation, whereas supernatants from ZE41 only had minor effects on cell viability. These results were in good agreement with our observations of cells in direct contact with the pre-treated alloys. 

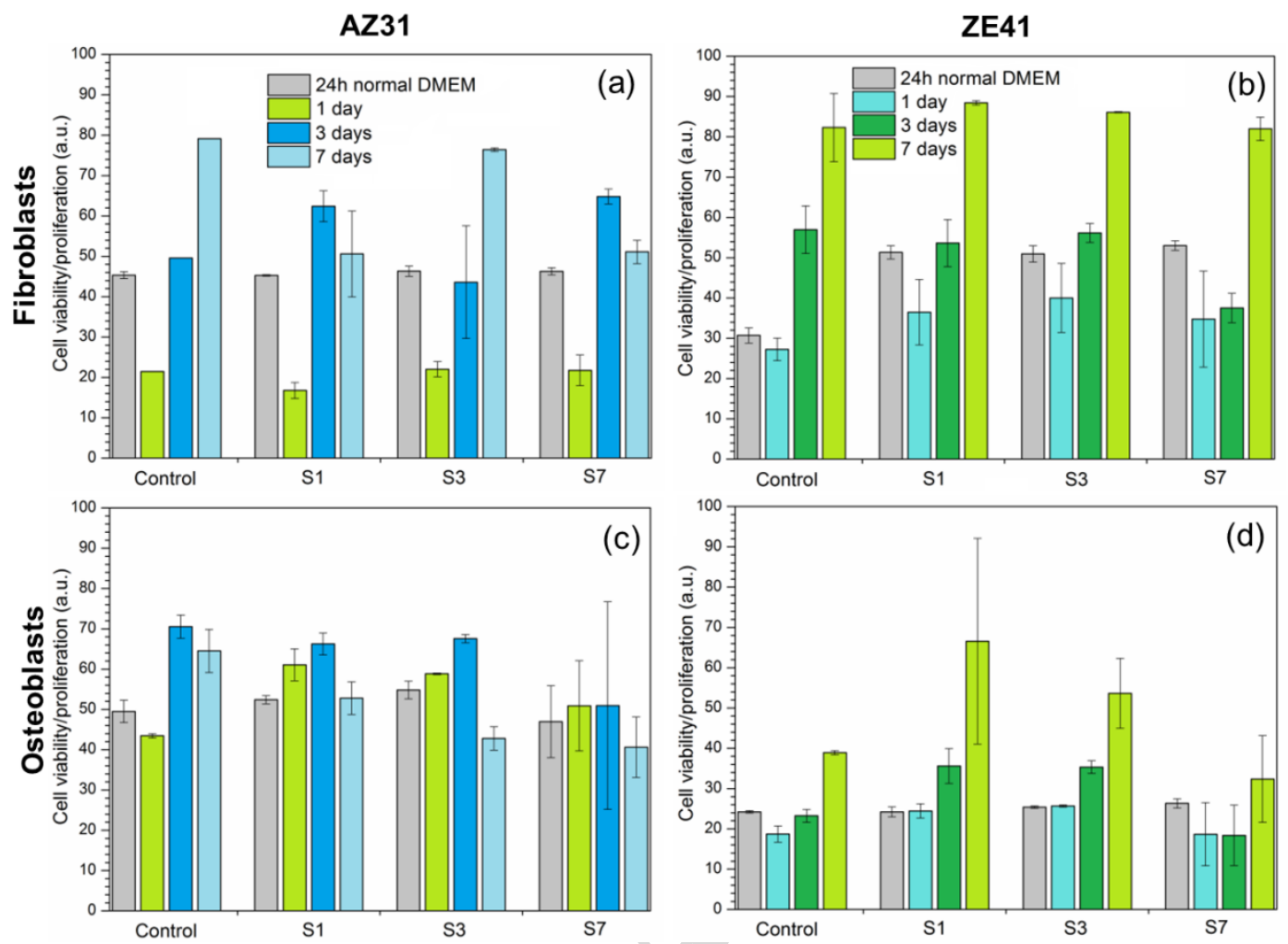

Fig. 8. Indirect contact assay results showing viability of both cell types for 7 days of culture in supernatants prepared by immersion of pre-treated alloys in cell culture medium at $37 \pm 1^{\circ} \mathrm{C}$. (a-b) Fibroblasts and (c-d) osteoblasts viability in supernatants with pre-treated AZ31 and ZE41, respectively. S1: supernatant collected at day 1, S3: at day 3 and S7: at day 7. Values are provided as mean values and error bars as standard deviations based on triplicates.

\section{$\underline{\text { 3.3.2 Cell viability on sol-gel coatings and bi-layered alloys }}$}

The effect of the different coatings on cell adhesion and proliferation was also studied. In the case of fibroblasts, when compared to the pre-treated substrates, the sol-gel coating showed little impact on the cellular adhesion (day 1) (Fig. 7a). However, the addition of collagen top layer dramatically promoted fibroblasts adhesion on ZE41_SC (by ca. 50\% compared to ZE41_S) but did not have a significant effect for AZ31_SC. Fibroblasts proliferation (day 3) was not evidenced on the AZ31 alloy, regardless the surface condition (Fig. 7a). In parallel, fibroblast proliferation was observed on ZE41_SC but not on ZE41_S. Worthy of notice is that when cell viability tests were performed on glass slides coated with the silane- $\mathrm{TiO}_{2}$ and the bi-layered systems (Fig. 9), similar trends were obtained at day 1, suggesting that the composition of the alloy had no significant impact on cell response on the short term, while the response at day 3 was different for ZE41 compared to glass, indicating that the reactivity of the alloy must be taken into account on a longer term. 

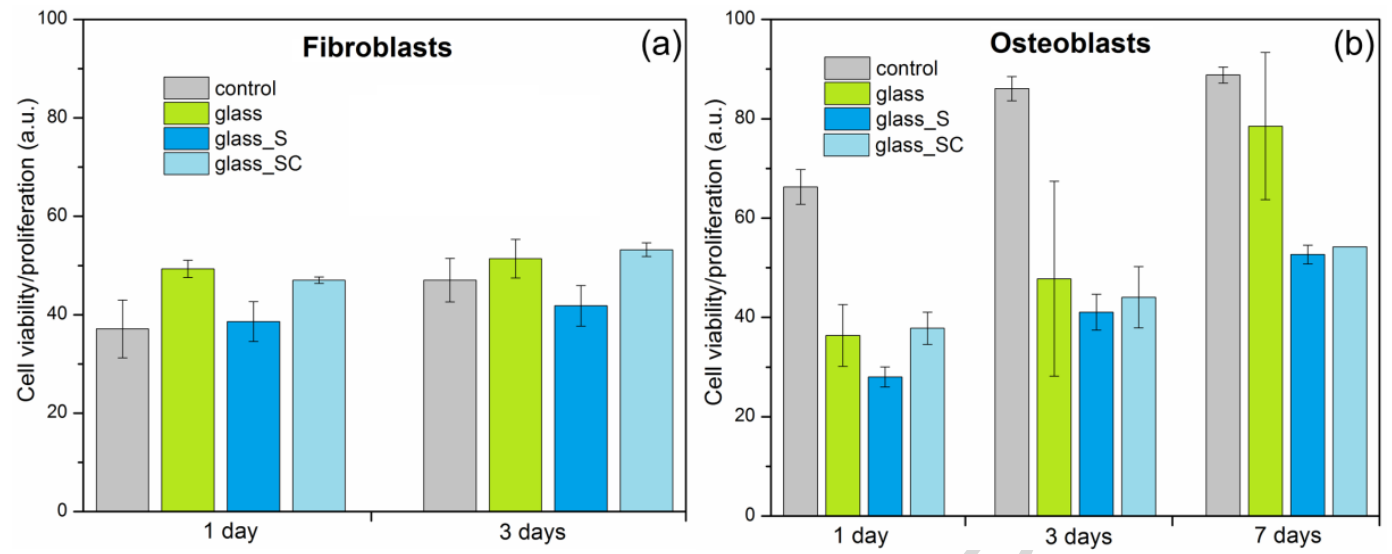

Fig. 9. Cell viability of (a) fibroblasts and (b) osteoblasts seeded on glass coated with the silane- $\mathrm{TiO}_{2}$ and the bilayered coating. S: silane- $\mathrm{TiO}_{2}$, SC: sol-gel+collagen. Values are provided as mean values and error bars as standard deviations based on triplicates.

Osteoblasts were more sensitive to the substrate composition (Fig. $7 \mathbf{b})$. The sol-gel coating on ZE41_S led to a sharp decrease of cell adhesion compared to the pre-treated alloy. The addition of collagen allowed the partial recovery of cell adhesion onto ZE41_SC and favoured osteoblasts proliferation over 7 days. In parallel, the sol-gel coating on AZ31_S had also a detrimental impact on osteoblast adhesion compared to the pre-treated alloy and had a dramatic negative effect on cell viability over 7 days. The latter effect was largely attenuated by the presence of collagen. Cell viability tests on coated glass slides confirmed that the sol-gel coating was detrimental to osteoblast proliferation on the long-term but, in this case, the benefits of an additional collagen layer was not evidenced (Fig. 9b). Altogether the results suggested that the effect of collagen was, at least for some part, related to its influence on the corrosion process and/or interaction with the corrosion products.

\subsection{Cellular morphology on the different surfaces}

The morphology of viable cells was evaluated after 1 day by fluorescence microscopy using a live/dead kit and after 3 and 7 days by SEM for fibroblasts and osteoblasts, respectively. When cultured on AZ31 for 1 day, fibroblasts exhibited a spindle-like shape, characteristic of a good adherence on the surface (inset Fig. 10a). In contrast, on ZE41, these cells exhibited a contractedrounded shape and red-fluorescing (i.e. dead) cells could even be observed, indicating a weak adhesion (inset Fig. 10b). After 3 days, fibroblasts were slightly spread on pre-treated AZ31 and 
showed finger-like protrusions known as lamellipodia (Fig. 10a) whereas, on ZE41, they were fully spread (Fig. 10b). This morphology was similar to that observed on plastic dishes, indicating good adhesion to the material surface.
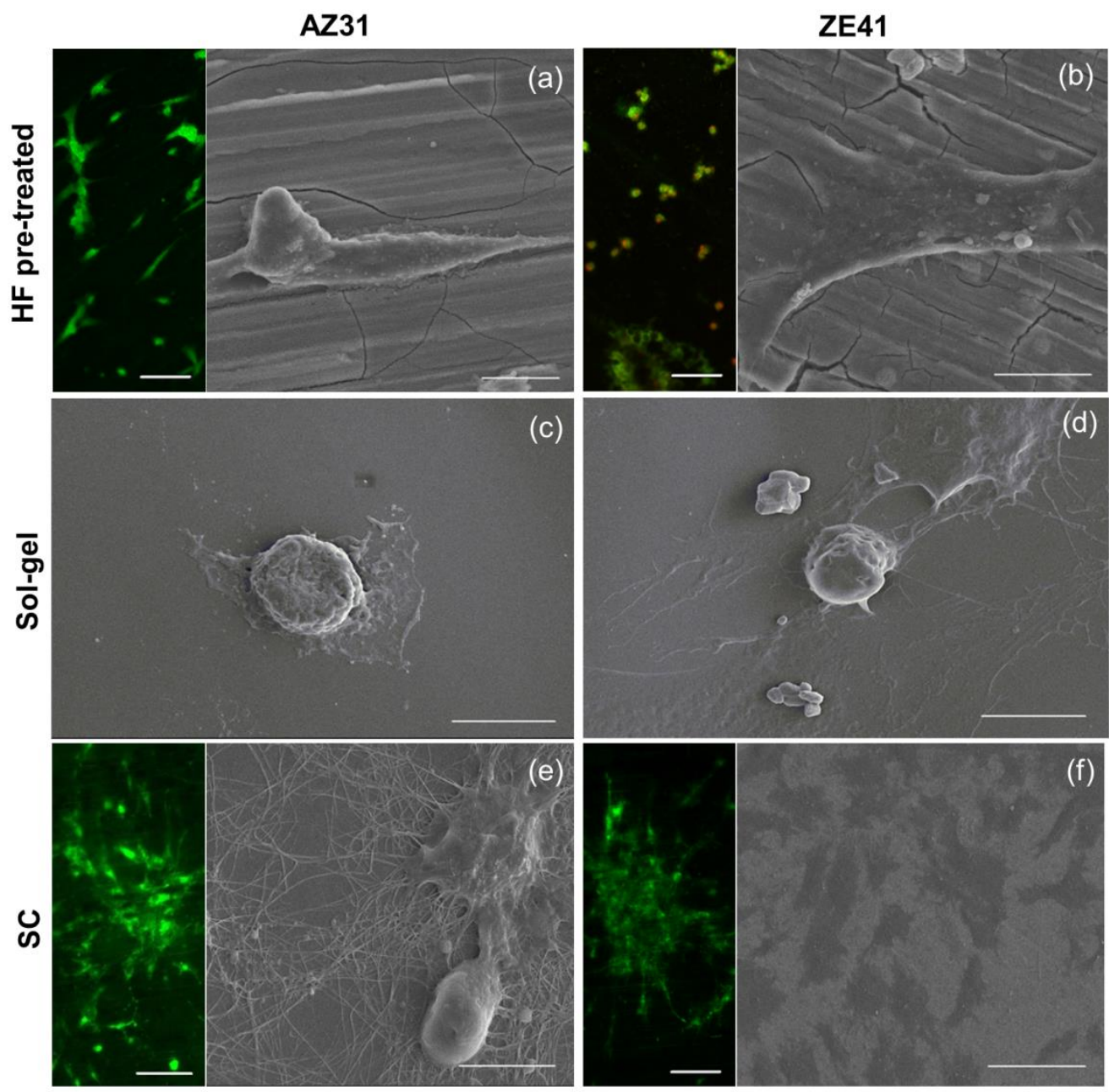

Fig. 10. Fibroblasts morphologies cultured on AZ31 (left hand column) and ZE41 (right hand column) with different surface modifications after 3 days of incubation (scale bar $10 \mu \mathrm{m}$, (f) $100 \mu \mathrm{m}$ ). The insets are fluorescence microscopy images of the cells using live/dead staining after 1 day (scale bar $100 \mu \mathrm{m}$ ). (a) AZ31, (b) ZE41, (c) AZ31_S, (d) ZE41_S, (e) AZ31_SC,(f) ZE41_SC.

The sol-gel coating drastically impacted the fibroblast morphology on AZ31_S and ZE41_S. After 3 days, cells had a rounded shape, typical of a weak attachment on the material surface (Fig. 10c-d). It is important to note that the same coating on glass slides allowed high fibroblast spreading (not shown). When the collagen layer was added, fibroblast morphology indicated that they recovered suitable adhesion and exhibited membrane protrusions forming clusters, indicative of good cell-to-cell contacts from day 1 (insets Fig. 10e-f) to day 3 (Fig. 10e- 
f). Importantly when AZ31_SC and ZE41_SC substrates were soaked in DMEM, a fibrillar collagen network (Fig. 10e and Fig. 11) was formed.

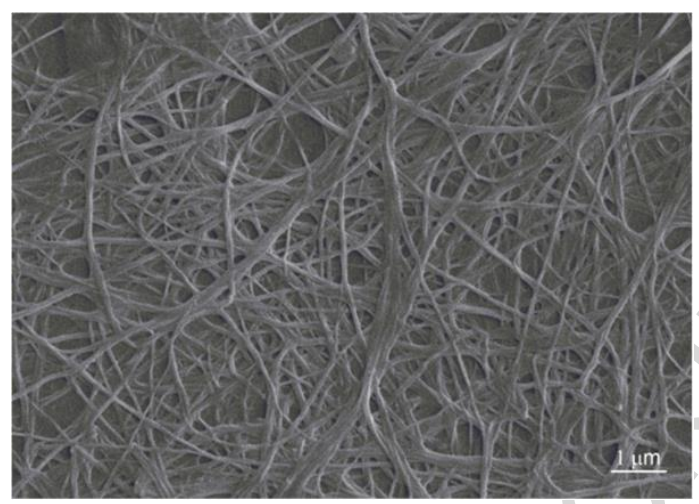

Fig. 11. SEM image of fibrillar collagen on ZE41_SC after immersion in DMEM for 7 days at $37^{\circ} \mathrm{C}(95 \%$ air with $\left.5 \% \mathrm{CO}_{2}\right)$.

Osteoblasts morphology after 1 day was similar to that of fibroblasts on ZE41 and AZ31 alloys (insets Fig. 12a-b). The morphologies changed after 7 days with the presence of rounded cells on AZ31 (Fig. 12a) and spread cells on ZE41 (Fig. 12b). Similarly to fibroblasts, osteoblasts adopted rounded shape on AZ31_S and ZE41_S, confirming the detrimental effect of the sol-gel coating on cell adhesion (Fig. 12c-d). However, as for fibroblasts, sol-gel coated glass slides allowed stronger adhesion and spreading of osteoblast cells (not shown). Osteoblasts seeded on AZ31_SC and ZE41_SC exhibited spread morphology and were found gathered in bundles, probably due to local proliferation, especially for the latter (Fig. 12e,f). The results confirmed the following assumptions: (i) the sol-gel coating was overall detrimental to cell adhesion compared to pre-treated alloy surfaces; (ii) the collagen coating allowed enhanced surface colonization; (iii) these effects depended upon the nature of the alloy, especially at intermediate times (around 3 days). 

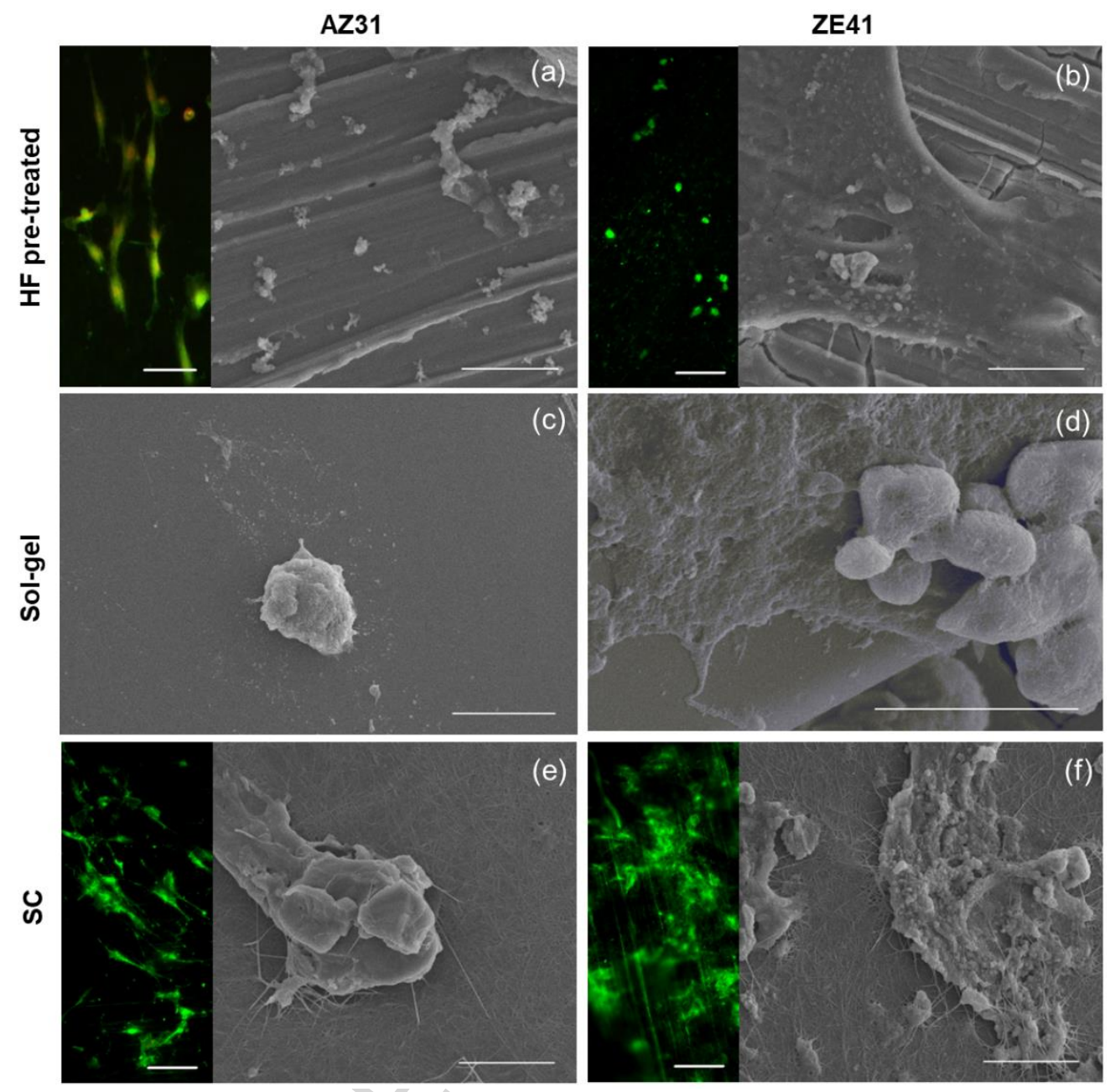

Fig. 12. Osteoblasts morphologies cultured on AZ31 (left hand column) and ZE41 (right hand column) with different surface modifications after 7 days of incubation (scale bar $10 \mu \mathrm{m}$, (d) $5 \mu \mathrm{m}$ ). The insets are fluorescence microscopy images of the cells using live/dead staining after 1 day (scale bar $100 \mu \mathrm{m}$ ). (a) AZ31, (b) ZE41, (c) AZ31_S, (d) ZE41_S, (e) AZ31_SC, (f) ZE41_SC.

\section{Discussion}

\subsection{Corrosion behaviour}

In this work, the corrosion experiments were performed in DMEM at $37^{\circ} \mathrm{C}$ as it corresponds to the conditions used to study adhesion and proliferation of fibroblasts and osteoblast cells. In these conditions, EDX examination after 7 weeks of testing suggested that $\mathrm{Mg}(\mathrm{OH})_{2}$ and $\mathrm{MgCO}_{3}$ were the major components of the corrosion layers, together with $\mathrm{CaCO}_{3}$ (Fig. 3). However, calcium phosphate phases, particularly modified HAP, could be detected after 1 week of testing only when the silane- $\mathrm{TiO}_{2}$ coating was present (Fig. 4). The fact that these aggregates were evidenced only in the presence of the silane- $\mathrm{TiO}_{2}$ coating (see $\mathbf{F i g}$. 3c-f) is in agreement with 
studies that previously demonstrated the ability of sol-gel derived silica and titania coatings to induce apatite nucleation [30].

Results showed that corrosion of AZ31 occurred rapidly leading to formation of a stable protective corrosion layer after 1 day (Fig. 2a). Interestingly, in SBF the formation of the stable layer for the pre-treated alloy was much slower than in DMEM and minimal protective effect of the sol-gel coating was reached after 4 weeks [25]. In parallel, ZE41 was slowly corroded in DMEM over 1 week before a stable protective layer was reached (Fig. 2b). With the sol-gel coating, the initial degradation was more marked (Fig. 2f); however, the stabilized layer of corrosion products provided effective protection against further corrosion in the long-term (Fig. 2f, $>2$ weeks). A similar trend was observed for ZE41 in SBF in a previous study [25] but wide variations in the impedance response with time were observed for sol-gel coated condition, suggesting more complex interplay between the corrosion products and the silane- $\mathrm{TiO}_{2}$ coating. This behavior points out that the efficiency of the sol-gel coating as a protective barrier against corrosion was, on the short term, strongly related to the kinetics of corrosion of the magnesium alloys and, on the long-term, to the nature of the corrosion products.

Several studies have shown that HAP coatings enhance corrosion resistance of $\mathrm{Mg}$ alloys [40-42]. For instance, Surmeneva et al. demonstrated improved corrosion resistance of HAPcoated AZ31 alloy in $3.5 \mathrm{wt} \% \mathrm{NaCl}$ solution at $37^{\circ} \mathrm{C}$ by polarization tests. Thin nanostructured HAP coatings of different thicknesses deposited on AZ31 by frequency magnetron sputtering technique resulted in more positive corrosion potential and reduced corrosion current density values when compared to the bare substrate $[40,41]$. It is worth to notice that in the present study we managed to build a coating that provides suitable conditions for in situ deposition of modified HAP sphero-aggregates. Since the modified HAP layer gradually forms along with the degradation of the alloy, it might significantly improve osseointegration due to the material surface ability to bind to the healing bone [43].

Corrosion kinetics can be explained as follows. As immersion time elapses, the electrolyte solution gradually permeated the coating reaching the underlying metal. At the metallic surface, $\mathrm{Mg}$ cations formed at the anodic sites, while $\mathrm{OH}^{-}$ions were released from the cathodic sites according to anodic and cathodic reactions (Eq. 1 to 3 ),
Cathodic reactions

$$
2 \mathrm{H}_{2} \mathrm{O}+2 \mathrm{e}^{-} \rightarrow 2 \mathrm{OH}^{-}+\mathrm{H}_{2} \uparrow
$$$$
\mathrm{O}_{2}+2 \mathrm{H}_{2} \mathrm{O}+4 \mathrm{e}^{-} \rightarrow 4 \mathrm{OH}^{-}
$$ 
Anodic reaction $\quad \mathrm{Mg} \rightarrow \mathrm{Mg}^{2+}+2 \mathrm{e}^{-}$

(Eq. 3)

which ultimately result in $\mathrm{Mg}(\mathrm{OH})_{2}$ precipitation. In parallel, due to the low solubility of calcium phosphates, and especially modified HAP, compared to carbonates, these phases precipitated firstly. In a second stage, since DMEM contains a high amount of $\mathrm{NaHCO}_{3}$, conversion of $\mathrm{Mg}(\mathrm{OH})_{2}$ and $\mathrm{CaP}$ into their carbonated form could occur. Some studies have demonstrated that glucose, which is present in DMEM, promoted formation of spherical-shaped CaP precipitates on the surface of pure Mg immersed in Hank's solution [29]. In the same way, it has been reported that carbonate ions in sodium chloride solution initially promoted dissolution of an AZ31 Mg alloy and then induced rapid surface passivation due to precipitation of magnesium carbonate phases [31].

From the resistance and the capacitive response of sol-gel coating, it was possible to suggest that initial coating swelling due to electrolyte uptake led to chemical and physical degradation of the sol-gel layer, decreasing its protective character. Further on, RSC of AZ31_SC increased (Fig. 6b) suggesting that precipitation/accumulation of corrosion products sealed the pores of the coating. As immersion elapsed, these pathways reactivated due to nucleation and growth of new defects in the coating and the corrosion processes could proceed. $\mathrm{R}_{\mathrm{IL}}$ (Fig. 6b) and $\mathrm{CPE}_{\mathrm{IL}}$ (Fig. 6c) confirmed that the corrosion layer of AZ31_SC provided a more effective corrosion protection to the substrate over immersion, probably due to its thickening and densification. A similar general trend was observed for ZE41_SC except for more significant variations between 2 and 4 weeks (Fig. 6d-e). Accordingly, the evolution of $\mathbf{R}_{\mathrm{ct}}$ (Fig. 6b) and $\mathrm{CPE}_{\mathrm{dl}}$ (Fig. 6c) showed that at early immersion, the corrosion response of AZ31_SC was governed by the corrosion resistance of the alloy; whereas, at advanced stages, the corrosion response was determined by the stability of the corrosion layer. In contrast, the response of ZE41_SC was mainly controlled by the barrier properties of the layer of corrosion products at all times, in agreement with the faster deterioration of the bi-layered coating on ZE41_SC (RSC and CPESC in Fig. 6d-e) compared to AZ31_SC that promoted formation of the corrosion layer at early stages. Differences in the stability of the corrosion layers of AZ31_SC and ZE41_SC could be due to differences in substrates bulk composition. For instance, Al could provide a stabilizing effect on the hydroxides formed on $\mathrm{Mg}$ alloys in chloride environments [8, 28].

Impedance results indicated that the most remarkable effect of the collagen layer was observed in the long-term (i.e. after 4 weeks, Fig. 2e-f), whereas it has no clear effect at the 
beginning of the immersion compared to the sol-gel coating. In a previous study [28] we demonstrated that at early immersion the outermost collagen layer does not have a detrimental effect on the silane- $\mathrm{TiO}_{2}$ barrier properties. Localized electrochemical impedance spectroscopy (LEIS) maps in $25 \%$ SBF of a special sample setup, half silane- $\mathrm{TiO}_{2}$ coated and half bi-layered with collagen, showed that there were no evident differences in corrosion activity between both sides during first 24h [28]. In addition, impedance results of SC coated alloys in both SBF [28] and in DMEM showed that in the long term (>2 weeks) corrosion performance is mainly governed by stability of the corrosion products (Fig. 2 and Fig. 3).

\subsection{Cellular behaviour}

Understanding the behaviour of fibroblasts and osteoblasts in contact with the different materials requires determining the various contributions from the chemistry of the alloys, the properties of the coatings, and their respective evolution upon corrosion.

The corrosion of AZ31 seemed to have a negative effect on the adhesion of fibroblasts and osteoblasts (Fig. 7). On the short term, cells succeeded to adhere and spread on the pre-treated alloy (insets in Fig. 10a and Fig. 12a). After 1 week when a stable layer of corrosion products was formed, the adhesion became weaker irrespective of the cell type. This detrimental effect seemed stronger for osteoblasts as these cells appeared rounded (Fig. 12a). The weak adherence could be due to the modification of the alloy topography or to the nature of the soluble products released during the corrosion process ( $\mathrm{Al}$ ions for instance). Indeed, indirect contact measurements showed that the supernatants of corroded AZ31 were cytotoxic. Previous investigations of osteoblasts (MC3T3-E1) and fibroblasts (L929) responses to HF-treated AZ31 showed no significant changes in cell viability but an oxidative stress effect was reported and attributed to detrimental interactions between cell membrane and the alloy surface [32]. This could explain the spindle (Fig. 10a) and rounded (Fig. 12a) shapes of fibroblasts and osteoblasts (Fig. 12a) on pre-treated AZ31, suggesting that cells preferred to minimize the membrane contact area with the alloy surface.

On the contrary, ZE41 corrosion seemed to have a positive effect on adhesion and proliferation of both cell types. While the cells poorly adhere to the native alloy (insets in Fig. 10b and Fig. 12b), osteoblasts and fibroblasts spread and proliferated on the corroded alloy (Fig. 10b and Fig. 12b). Thus, it can be suggested that the corrosion layer, incorporating magnesium and calcium compounds, can be more favorable that the native pre-treated alloy surface, especially for 
osteoblasts, explaining cell proliferation after 3 and 7 days compared to day 1 (Fig. 7). Moreover, corrosion products generated by the ZE41 alloy have a positive effect on cell viability, as previously mentioned.

Overall the silane- $\mathrm{TiO}_{2}$ coating showed a detrimental effect on fibroblasts and osteoblasts adhesion and proliferation on AZ31_S and ZE41_S (Fig. 7). It can be noticed that the time scale of the biological tests, i.e. over 1 week, corresponded to the conditions where the alloy corrosion was detrimental to the sol-gel coating stability. Indeed, control experiments performed on glass slides (Fig. 9) demonstrated that the sol-gel coating was merely detrimental to cell activity on its own. Then, after one week, the corrosion layers on the sol-gel coated alloys were not mature enough to establish a new barrier effect. This impacted on the cell morphology, as all observed cells appeared rounded (Fig. 10c-d and Fig. 12c-d), evidencing poor adhesion strength. The material topography could hinder fibroblasts proliferation, while maintaining the number of adherent cells. Unlike fibroblasts, the adhesion ability and proliferation of osteoblasts were impacted by the silane- $\mathrm{TiO}_{2}$ coating on both alloys. This negative effect was stronger on AZ31_S as the cell population decreased from day 3 to day 7 while it increased on ZE41_S (Fig. 7). This could be due to differences in topography or to the positive effect of the ZE41_S corrosion products on the cells fate.

The addition of collagen largely improved fibroblasts and osteoblasts viability, particularly on the ZE41_SC (Fig. 7). The improved fibroblast and osteoblast viability observed after collagen deposition can be related to the observed beneficial effect of this top-layer on the stability and protective effect of the sol-gel coating. Moreover upon contact with DMEM, the initial coating underwent fibrillogenesis (Fig. 11) [33]. Collagen fibrils are the natural substrate for osteoblasts and fibroblasts, which allows cell adhesion and survival. Hence, the collagen layer offers topological and biochemical conditions favoring cell viability. Investigations of the effect of fibrillar and non-fibrillar collagen coatings applied on Ti showed that fibrillar assembly of collagen significantly improved the level of osteoblasts (MG63) attachment and proliferation [34]. This work demonstrates that the collagen layer forms a fibrillar network trapping cells in an open 3D mesh (Fig. 10e-f and Fig. 12e). This can contribute both to improve cell adhesion but also protect them in some ways against adverse corrosion products [35]. 


\section{Conclusion}

This study presents a novel simple route to efficiently control the corrosion degradation of $\mathrm{Mg}$ alloys using a silane- $\mathrm{TiO}_{2} /$ collagen hybrid coating that provides a biomimetic method for in situ deposition of modified hydroxyapatite. There is a combined effect of the bi-layered coating and the nature of the alloys on their final corrosion response and on the cellular response. The silane- $\mathrm{TiO}_{2}$ provides effective corrosion protection to the alloys at early immersion in DMEM, while a stabilized layer of corrosion products provides additional barrier effect at long immersion periods. The collagen layer provides suitable conditions for cell attachment and proliferation. Then, the higher corrosion resistance and improved cell response along with good potential for bone formation show the high potential of this biofunctional coating to engineer $\mathrm{Mg}$ alloys as biodegradable implants for bone reparation. In particular, it can be useful to tune the biodegradation rate of $\mathrm{Mg}$-based plates for bone fracture fixation and improve their binding to the tissue under repair. The here-reported findings also contribute to elucidate the corrosion processes of $\mathrm{Mg}$ alloys in cell culture conditions in both short and long-term, providing more reliable preliminary in vitro assessment of their in vivo behaviour.

\section{Funding}

This work was supported by the project 2012-05-EM from the International Doctoral School in Functional Materials IDS-FunMat and the financial support by Fundação para a Ciência e a Tecnologia (FCT) to CQE (UID/QUI/00100/2013).

\section{Acknowledgments}

The authors thank Isabelle Génois from LCMCP and Alicja Balkowiec and Janusz Rebis from Warsaw University of Technology for the technical support.

\section{References}

[1] Witte F. The history of biodegradable magnesium implants: A review. Acta Biomater 2010;6:1680-1692. DOI: 10.1016/j.actbio.2010.02.028

[2] Tan L., Yu X., Wan P., Yang K. Biodegradable Materials for Bone Repairs: A Review. J. Mater. Sci. Technol 2013;29:503-513. https://doi.org/10.1016/j.jmst.2013.03.002 
[3] Staiger M.P., Pietak A.M., Huadmai J., Dias G. Magnesium and its alloys as orthopaedic biomaterials: A review. Biomaterials 2006;27:1728-1734. DOI: 10.1016/j.biomaterials.2005.10.003

[4] Song G. Control of biodegradation of biocompatible magnesium alloys. Corros. Sci 2007;49:1696-1701. https://doi.org/10.1016/j.corsci.2007.01.001

[5] Zhen Z., Xi T.F., Zheng Y.F. A review on in vitro corrosion performance test of biodegradable metallic materials. Trans. Nonferrous Met. Soc. China English Ed. 2013;23:2283-2293. https://doi.org/10.1016/S1003-6326(13)62730-2

[6] Fox C., Ramsoomair D., Carter C. Magnesium: its proven and potential clinical significance. South. Med. J. 2002;94:1195-1201. DOI: 10.1097/00007611-200112000-00013

[7] Wu L., Feyerabend S., Schilling A.F., Willumeit-Römer R., Luthringer B.J. Effects of extracellular magnesium extract on the proliferation and differentiation of human osteoblasts and osteoclasts in co-culture. Acta Biomater 2015;27:294-304. https://doi.org/10.1016/j.actbio.2015.08.042

[8] Witte F., Kaese V., Haferkamp H., Switzer E., Meyer-Lindenberg A., Wirth C.J., Windhagen $\mathrm{H}$. In vivo corrosion of four magnesium alloys and the associated bone response. Biomaterials 2005;26:3557-3563. https://doi.org/10.1016/j.biomaterials.2004.09.049

[9] Chang P.C., Liu B.Y., Liu C.M., Chou H.H., Ho M.H., Liu H.C., Wang D.M., Hou L.T. Bone tissue engineering with novel rhBMP2-PLLA composite scaffolds. J. Biomed. Mater. Res. A 2007;81:771-780. DOI: 10.1002/jbm.a.31031

[10] Rojaee R., Fathi M., Raeissi K. Controlling the degradation rate of AZ91 magnesium alloy via sol-gel derived nanostructured hydroxyapatite coating. Mater. Sci. Eng. C 2013;33:38173825. https://doi.org/10.1016/j.msec.2013.05.014

[11] Zomorodian A., Garcia M.P., Moura e Silva T., Fernandes J.C.S.,. Fernandes M.H.,. Montemor M.F. Biofunctional composite coating architectures based on polycaprolactone and nanohydroxyapatite for controlled corrosion activity and enhanced biocompatibility of magnesium AZ31 alloy, Mater. Sci. Eng. C. 2015;48:434-443. https://doi.org/10.1016/j.msec.2014.12.027

[12] Hornberger H., Virtanen S., Boccaccini A.R. Biomedical coatings on magnesium alloys - A review, Acta Biomater 2012;8:2442-2455. https://doi.org/10.1016/j.actbio.2012.04.012 
[13] Pan Y.K., Chen C.Z., Wang D.G., Zhao T.G. Effects of phosphates on microstructure and bioactivity of micro-arc oxidized calcium phosphate coatings on $\mathrm{Mg}-\mathrm{Zn}-\mathrm{Zr}$ magnesium alloy, Colloids Surf. B Biointerfaces 2013;109:1-9. https://doi.org/10.1016/j.colsurfb.2013.03.026

[14] Dorozhkin S.V. Calcium orthophosphate coatings on magnesium and its biodegradable alloys, Acta Biomater 2014;10:2919-2934. https://doi.org/10.1016/j.actbio.2014.02.026

[15] Raphel J., Karlsson J., Galli S., Wennerberg A., Lindsay C., Haugh M.G., Pajarinen J., Goodman S.B., Jimbo R., Andersson M., Heilshorn H.C. Engineered protein coatings to improve the osseointegration of dental and orthopaedic implants. Biomaterials 2016;83:269-282. https://doi.org/10.1016/j.biomaterials.2015.12.030

[16] Smith J.R., Lamprou D.A. Polymer coatings for biomedical applications: a review, Transactions of the IMF 2014;92:9-19. DOI: 10.1179/0020296713Z.000000000157

[17] Kunjukunju S., Roy A., Ramanathan M., Lee B., Candiello J.E., Kumta P.N. A layer by-layer approach to natural polymer-derived bioactive coatings on magnesium alloys, Acta Biomater. 2013;9:8690-8703. https://doi.org/10.1016/j.actbio.2013.05.013

[18] Zhao N., Zhu D. Collagen Self-Assembly on Orthopedic Magnesium Biomaterials Surface and Subsequent Bone Cell Attachment, PLoS ONE 2014;9:e110420. https://doi.org/10.1371/journal.pone.0110420

[19] Morra M., Cassinelli C., Cascardo G., Cahalan P., Cahalan L., Fini M., Giardino R. Surface engineering of titanium by collagen immobilization. Surface characterization and in vitro and in vivo studies. Biomaterials 2003;24:4639-4654. https://doi.org/10.1016/S0142-9612(03)00360-0 [20] De Jonge L.T., Leeuwenburgh S.C., van den Beucken J.J., te Riet J., Daamen W.F., Wolke J.G., Scharnweber D., Jansen J.A. The osteogenic effect of electrosprayed nanoscale collagen/calcium phosphate coatings on titanium. Biomaterials 2010;31:2461-2469. DOI: 10.1016/j.biomaterials.2009.11.114

[21] Fischer U., Hempel U., Becker D., Bierbaum S., Scharnweber D., Worch H., Wenzel K.W., Transforming growth factor beta1 immobilized adsorptively on Ti6Al4V and collagen type I coated Ti6Al4V maintains its biological activity. Biomaterials 2003;24:2631-2641. https://doi.org/10.1016/S0142-9612(03)00068-1

[22] Alghamdi H.S., van Oirschot B., Bosco R., van den Beucken JJJ.P., Aldosari A.A.F., Anil S., Jansen J.A., Biological response to titanium implants coated with nanocrystals calcium phosphate 
or type 1 collagen in a dog model. Clin. Oral Implant. Res. 2012;24:475-483. DOI: 10.1111/j.16000501.2011.02409.x

[23] Mushahary D., Wen C., Kumar J.M., Lin J., Harishankar N., Hodgson P., Pande G., Li Y., Collagen type-I leads to in vivo matrix mineralization and secondary stabilization of $\mathrm{Mg} \mathrm{Zr}-\mathrm{Ca}$ alloy implants, Colloids Surf. B Biointerfaces. 2014;122:719-728. https://doi.org/10.1016/j.colsurfb.2014.08.005

[24] Junjun Z., Lin J., Li J., Weng W., Cheng K., Wang H., Alternating potentials assisted electrochemical deposition of mineralized collagen coatings, Colloids Surf. B Biointerfaces 2015;136:479-487. https://doi.org/10.1016/j.colsurfb.2015.09.050

[25] Córdoba L.C., Montemor M.F., Coradin T. Silane/TiO 2 coating to control the corrosion rate of magnesium alloys in simulated body fluid, Corros. Sci. 2016;104:152-161. https://doi.org/10.1016/j.corsci.2015.12.006

[26] Hélary C., Foucault-Bertaud A., Godeau G., Coulomb B., Giraud-Guille M.M. Fibroblast populated dense collagen matrices: cell migration, cell density and metalloproteinases expression. Biomaterials 2005;26:1533-1543. https://doi.org/10.1016/j.biomaterials.2004.05.016

[27] S.N. (2015) Lafuente B, Downs R T, Yang H, The power of databases: the RRUFF project, 2015. rruff.info.

[28] L.C. Córdoba, A. Marques, M. Taryba, T. Coradin, F. Montemor, Hybrid coatings with collagen and chitosan for improved bioactivity of Mg alloys. Surf. Coat. Technol. (2017), http://dx.doi.org/10.1016/j.surfcoat.2017.08.062.

[29] Zeng R.-C., Li X.-T., Li S.-Q., Zhang F., Han E.-H., In vitro degradation of pure Mg in response to glucose, Sci. Rep. 2015;5:13026. DOI: 10.1038/srep13026

[30] Wang X., Hayakawa S., Tsuru K., Osaka A. Bioactive titania-gel layers formed by chemical treatment of $\mathrm{Ti}$ substrate with a $\mathrm{H}_{2} \mathrm{O}_{2} / \mathrm{HCl}$ solution, Biomaterials 2002;23:1353-1357. https://doi.org/10.1016/S0142-9612(01)00254-X

[31] Xin Y., Huo K., Tao H., Tang G., Chu P.K. Influence of aggressive ions on the degradation behavior of biomedical magnesium alloy in physiological environment, Acta Biomater. 2008;4:2008-2015. DOI: 10.1016/j.actbio.2008.05.014

[32] Lozano R.M., Pérez-Maceda B.T., Carboneras M., Onofre-Bustamante E., García-Alonso M.C., Escudero M.L. Response of MC3T3-E1 osteoblasts, L929 fibroblasts, and J774 
macrophages to fluoride surface-modified AZ31 magnesium alloy, J. Biomed. Mater. Res. - Part A. 2013;101:2753-2762. DOI: 10.1002/jbm.a.34579

[33] Trelstad R.L., Hayashi K., Gross J. Collagen fibrillogenesis: intermediate aggregates and suprafibrillar order, Proc. Natl. Acad. Sci. U. S. A. 1976;73:4027-4031. DOI: 10.1073/pnas.73.11.4027

[34] Kim H.W., Li L.H., Lee E.J., Lee S.H., Kim H.E. Fibrillar assembly and stability of collagen coating on titanium for improved osteoblast responses, J. Biomed. Mater. Res. - Part A. 2005;75:629-638. DOI: 10.1002/jbm.a.30463

[35] Zhao N., Workman B., Zhu D. Endothelialization of novel magnesium-rare earth alloys with fluoride and collagen coating, Int. J. Mol. Sci. 2014;15:5263-5276. DOI: 10.3390/ijms15045263 [36] Y. Zhu, G. Wu, Y.H. Zhang, Q. Zhao, Growth and characterization of $\operatorname{Mg}(\mathrm{OH})_{2}$ film on magnesium alloy AZ31, Appl. Surf. Sci. $257 \quad$ (2011) 6129-6137. DOI:10.1016/j.apsusc.2011.02.017.

[37] R.C. Zeng, Y. Hu, S.K. Guan, H.Z. Cui, E.H. Han, Corrosion of magnesium alloy AZ31: The influence of bicarbonate, sulphate, hydrogen phosphate and dihydrogen phosphate ions in saline solution, Corros. Sci. 86 (2014) 171-182. DOI:10.1016/j.corsci.2014.05.006.

[38] C. Combes, C. Rey, Amorphous calcium phosphates: Synthesis, properties and uses in biomaterials, Acta Biomater. 6 (2010) 3362-3378. DOI:10.1016/j.actbio.2010.02.017.

[39] M. Manoj, R. Subbiah, D. Mangalaraj, N. Ponpandian, C. Viswanathan, K. Park, Influence of Growth Parameters on the Formation of Hydroxyapatite (HAp) Nanostructures and Their Cell Viability Studies, Nanobiomedicine. (2015) 1. DOI:10.5772/60116.

[40] M.A. Surmeneva, R.A. Surmenev, Microstructure characterization and corrosion behavior of a nanohydroxyapatite coating deposited on AZ31 magnesium alloy using radio frequency $\begin{array}{lllll}\text { magnetron } & \text { sputtering, } & \text { Vacuum } & 117 & \text { 60-62. }\end{array}$ http://dx.doi.org/10.1016/j.vacuum.2015.04.004

[41] T. Mukhametkaliyev, M. Surmeneva, R. Surmenev, B. K. Mathan, Hydroxyapatite Coating on Biodegradable AZ31 and Mg-Ca Alloys Prepared by RF-Magnetron Sputtering, AIP Conference Proceedings 1688, 030006 (2015); DOI: 10.1063/1.4936001 
[42] S. Hiromoto, A. Yamamoto, High corrosion resistance of magnesium coated with hydroxyapatite directly synthesized in an aqueous solution, Electrochim. Acta 54 (2009) 70857093; DOI:10.1016/j.electacta.2009.07.033

[43] C. Castellani, R. A. Lindtner, P. Hausbrandt, E. Tschegg, S. E. Stanzl-Tschegg, G. Zanoni, S. Beck, A.-M. Weinberg, Bone-implant interface strength and osseointegration: Biodegradable magnesium alloy versus standard titanium control, Acta Biomater. 7 (2011) 432-440 DOI: 10.1016/j.actbio.2010.08.020 
Hybrid
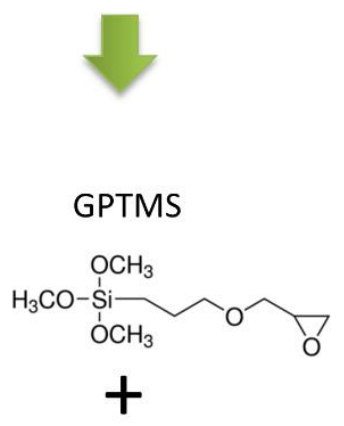

Titanium IV

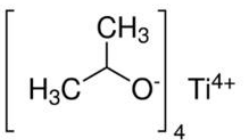

\section{Bi-layered}

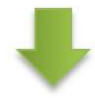

Type I Collagen Sol-gel

Mg Alloy

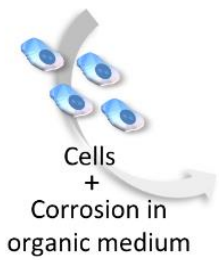

Multifunctional coating

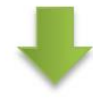

\section{Collagen}

Cell adhesion/proliferation

Silane- $\mathrm{TiO}_{2}$

Barrier properties

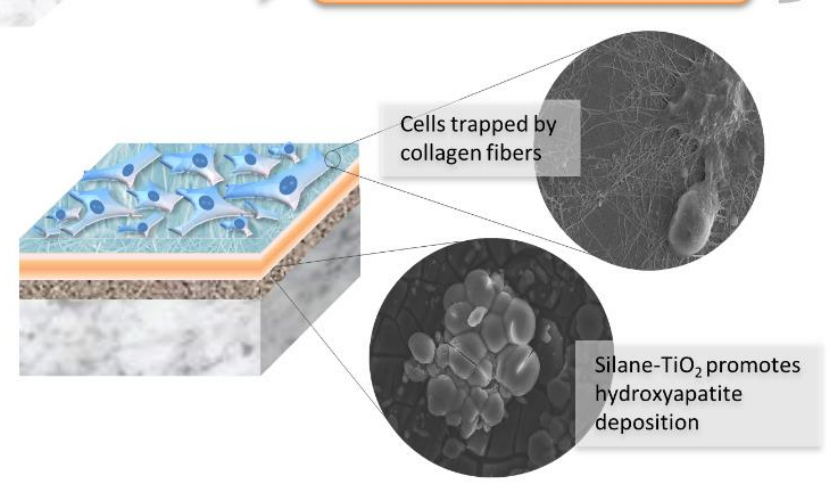

Graphical abstract 


\section{Highlights}

○ A novel bi-layered multifunctional coating of easy implementation was developed.

- Silane- $\mathrm{TiO}_{2}$ provides suitable conditions for in situ deposition of modified hydroxyapatite.

○ Fibrillar collagen improved cell growth and proliferation on silane- $\mathrm{TiO}_{2}$.

- Corrosion mechanisms in organic medium in the long term are elucidated. 